\title{
Digital technologies and robotization as a factor of sustainable tourism development
}

\author{
L. V. Semenova, and S. M. Konyushenko \\ Immanuel Kant Baltic Federal University, Kaliningrad, Russia
}

\begin{abstract}
The issues of digital technology integration in the tourism and hospitality industry, which have an impact on the sustainable development of both the entire industry and its individual subjects, are considered. The main digital services and tools functioning in the market of tourist services are analyzed.
\end{abstract}

\section{Introduction}

In today's world, technology and travel are the perfect combination, and their combination plays an important role in the way people travel: from the vacation place they choose, all the way to the time spent and entertainment at the location. Currently, there are two global trends in the world that have a direct impact on the field of tourism. The first is the environmental ecology: people are paying more and more attention to environmentally friendly materials, abandoning plastic and paper, which has affected tourism, including: paper guides and maps are going away, and digital devices are taking their place. The global coronavirus pandemic (COVID-19) has significantly affected both people's lives in general and tourism. With onset of isolation, organizations in various fields have opened up online access to many materials, documents, and platforms. People were encouraged to travel in an online format to museums, cities, hotel accommodations, etc. This was an important prerequisite for active digitalization of all elements of the hospitality and tourism industry. Currently, this trend continues to grow. Digital services and applications make it possible both to visit sites that no longer exist and to create an immersive tour for tourists with a full dipping into the past. Business digitalization is often a major source of competitive advantage for tour companies, promoting efficiency, productivity and differentiation to meet a wide variety of needs.

\section{Materials and methods}

The study is based on a systematic approach to its object (digitalization process of tourism business that forms the sustainable development of a tourist destination) and the subject (main technologies that form the trends of tourism development). 


\section{Results and discussion}

Let us consider some of the technological advances that are currently affecting the tourism industry and, according to various studies, will bring significant short-term changes to this sector $[1 ; 2]$.

1. Mobile technologies. Travelers are faced with a myriad of decisions as they plan their trip. Challenges begin when people start dreaming about the trip. Also, decisions are faced in planning, booking and even during the actual trip. When such moments happen, people are increasingly turning to their smartphones for immediate answers to travel questions. Mobile travel visits are up $48 \%$ in the past year, and because mobile devices help people find what they need faster, the time spent on a session on mobile travel sites is down $7 \%$, while mobile web conversion rates to travel sites are up $88 \%$. This shows that every year the phone is a simple, fast, and most importantly used device for planning and implementing the trip [3]. Currently, there are many applications for mobile devices where the user can fully plan their journey: from buying transport tickets and booking a hotel, to what needs to be put in a suitcase for the trip. For many users who are good with a phone, planning the trip is done this way.

2. Augmented reality. Augmented reality - a technology of adding, introducing into real life, in the three-dimensional field of human perception of virtual information, which is perceived as elements of real life [4]. The goal of augmented reality technology is to give people impressions that they will remember for a long time. This function works on smartphones, tablets, augmented reality glasses and other gadgets.

The use of augmented reality has a number of advantages:

- The combination of virtual reality with real life causes a strong emotional effect, which has a positive effect on the marketing campaign of organization.

- The information comes to the user in an easy and playful way that allows highquality memorization of the material.

- Unlike virtual reality, augmented reality technology can be used with the help of existing gadgets.

- After using the application with augmented reality, as mentioned above, there are strong emotions that the user will continue to share with his environment. In this way, the "viral effect" of advertising is born.

The result of using augmented reality in your business is the expansion of users.

In tourism, augmented reality is used to compare new and old views of buildings, streets, cities, attractions, and things like that. In addition, many museums use this technology to allow the visitor to delve into history, to explore the details of sights and events. Also, an integral role in journey is played by navigation in an unfamiliar city, in this case, applications with augmented reality will help navigate and find the right place.

3. Internet of Things. The Internet of Things - a network of physical objects that have built-in technologies that allow them to interact with the external environment, transmit information on their state and receive data from the outside [5].

The tourism industry, using the technology of the Internet of Things, can derive benefit. The Internet of Things can provide further automation, greater personalization, and a better customer experience. It can also simplify the day-to-day tasks associated with running a hotel or travel company.

The use of smart devices can help optimize the physical state of a hotel and its rooms and can reduce energy costs. On planes, sensors can even be used to alert staff when someone's alarm level rises above a certain level. Meanwhile, the Internet of Things can 
give tourists more control and access to information through their smartphone. For example, airplane passengers can track their luggage [6].

4. Artificial intelligence. Artificial intelligence (AI) - a broad branch of computer technology that deals with the creation of intelligent machines capable of performing tasks that usually require human intelligence [7].

Artificial intelligence is extremely close to the automation solutions that have been provided in almost every industry in today's world. It includes manufacturing machines that can think intelligently like humans. The tourism industry has noticed significant changes in its processes thanks to artificial intelligence. This has made many processes in this industry extremely fast and convenient.

The development of artificial intelligence or machine learning is constantly making changes in the entire travel and tourism industry, and the main factors affecting the travel and tourism industry include the following:

- hotel reservations;

- chatbots: first of all, this technology exists for instant messaging to help its customers at any time; the main reason for the success of chatbots in this industry is the demand for fast and accurate responses.

- $\quad$ room service: voice assistants and chatbots have entered hotel rooms to provide customers with top-level service. Well-known brands have a special assistant with special names that everyone remembers.

- data analysis: artificial intelligence also helps in data processing and analysis. As in any other industry, the main work of AI here is also related to collecting data about customers. It interprets their information, needs, and preferences to provide businesses with data from which they can strategize their policies [8].

5. Big data. Big data - a variety of tools, approaches and methods for processing both structured and unstructured data in order to use them for specific tasks and goals [9]. The organization uses data on its guests to figure out what the best target is for marketing campaigns. First of all, they verify their database to look at the amount spent, the trip reason, the country of origin and check this information with publicly available data from government sources to develop the most appropriate customer profile and achieve a higher success rate. In this way, they improve the segmentation of their campaigns to increase their effectiveness and optimize the investment required for these campaigns.

6. Wearable devices that are becoming increasingly popular: smart watches, bracelets, smartphones, etc. Wearable technology is fast becoming one of the best innovations in the today's world. Wearable technology mainly refers to an advanced form of technology that can be worn on a day-to-day basis.

Wearable technologies are designed taking into account the consumers' convenience, and the goal is to improve the overall traveler experience. A global survey conducted by SITA found that almost $77 \%$ of travelers would be happy with airlines using wearable technology, such as smartwatches or Google Glass. In addition, these technologies have also proven to be very useful for travel agents around the world because they offer agents another way to communicate with their customers in online mode.

Travel agents around the world can use wearable technology to meet the growing need for more efficient and personalized services. They can also use wearable technology to personalize holiday packages, adapt each route and improve the way they communicate with their customers. Since customers are constantly looking for solutions that offer them the information they have at their fingertips, this promotion should be a major boon to travel agents and the travel industry as a whole [10].

Every year the world becomes more digital, technologies are updated and take over different areas of society. To ensure that travel companies do not lose popularity and are in demand among customers, organizations should implement technologies in their business. 
According to published UNWTO statistics, the number of tourists increases every year. International arrivals were up $3.8 \%$ in 2019 over the previous year. 2019 was the tenth consecutive year of steady growth since 2009. UNWTO estimates that destinations worldwide accounted for about 1.5 billion arrivals in 2019, an increase of approximately 54 million over the previous year [11].

The tourism industry - an important economical sector not only of one state, but also of the world as a whole. According to statistics, from 2006 to 2019, there is an increase in the contribution of the tourism industry to world GDP.

\begin{tabular}{|lrc|}
\hline & Direct contribution & Total contribution \\
\hline 2006 & $1,629.02$ & $5,160.35$ \\
\hline 2009 & $1,794.88$ & $5,803.03$ \\
\hline 2007 & $1,809.37$ & $5,765.03$ \\
\hline 2010 & $1,911.51$ & $6,108.56$ \\
\hline 2008 & $1,928.47$ & $6,259.57$ \\
\hline 2011 & $2,157.06$ & $6,925.29$ \\
\hline 2012 & $2,207.37$ & $7,094.29$ \\
\hline 2013 & $2,304.81$ & $7,432.19$ \\
\hline 2015 & $2,320.93$ & $7,444.04$ \\
\hline 2016 & $2,381.1$ & $7,650.17$ \\
\hline 2014 & $2,388.31$ & $7,674.79$ \\
\hline 2017 & $2,567.88$ & $8,240.74$ \\
\hline 2018 & $2,750.65$ & $8,810.96$ \\
\hline 2019 & $2,892.94$ & $9,258.29$ \\
\hline
\end{tabular}

Fig. 1. Direct and total contribution of travel and tourism to GDP from 2006 to 2019 [12], USD.

The direct contribution of tourism and travel to global GDP in 2019 was just under 2,893 billion US dollars. Taking into account that the total contribution to global GDP in 2019 was just over 9,258 billion US dollars. The data show that the tourism industry brings a large profit, which contributes to the development of the state financially. From which inference should be drawn that tourism needs to be developed in the country, in the region. However, in order to attract tourists to a particular area, it is needed to consider several factors: seasonality, attractiveness of the area, transport accessibility, financial accessibility, etc. Also the ability to interest and impress newcomers is needed. This can be helped by technologies that are becoming easier to use every year. In addition, with the help of technology, many unreal things can be shown in real life. This option has a positive effect on the emotional background of tourists. 


\section{Number of mobile phone users worldwide from 2015 to 2020}

(in billions)

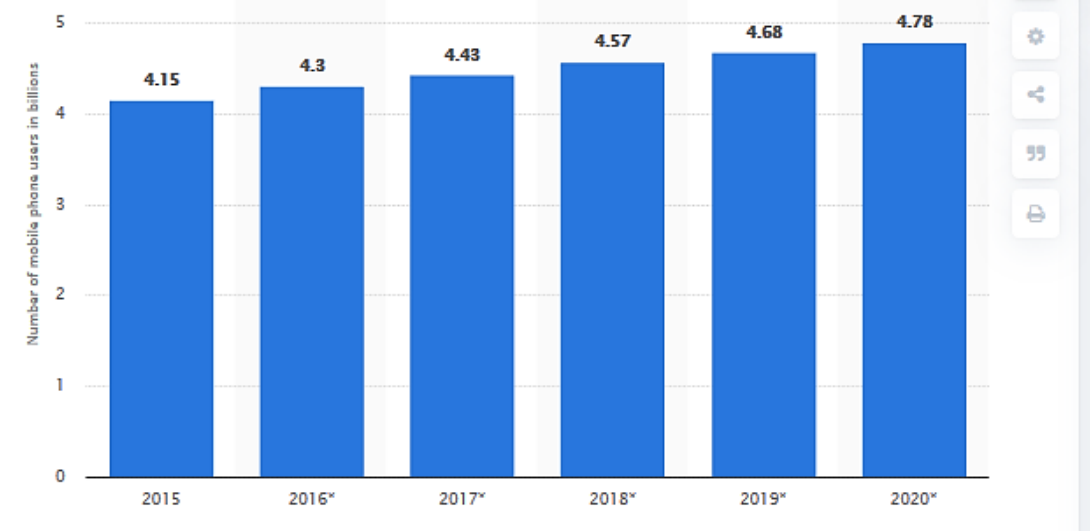

Fig. 2. Number of mobile phone users worldwide from 2015 to 2020 [13], number in billion

Statistics present the total number of mobile phone users worldwide from 2015 to 2020. Every year, the number of users increases, and the role of mobile applications increases accordingly. By integrating mobile devices into everyday life, users are getting closer to tourism, simplifying many formalities. Mobile applications in the field of tourism bring great profits: in 2019, the tourism sector in the world earned almost 18 billion US dollars due to app downloads. Revenue is expected to grow.

\section{Worldwide mobile app revenues in 2014 to 2023}

(in billion U.S. dollars)

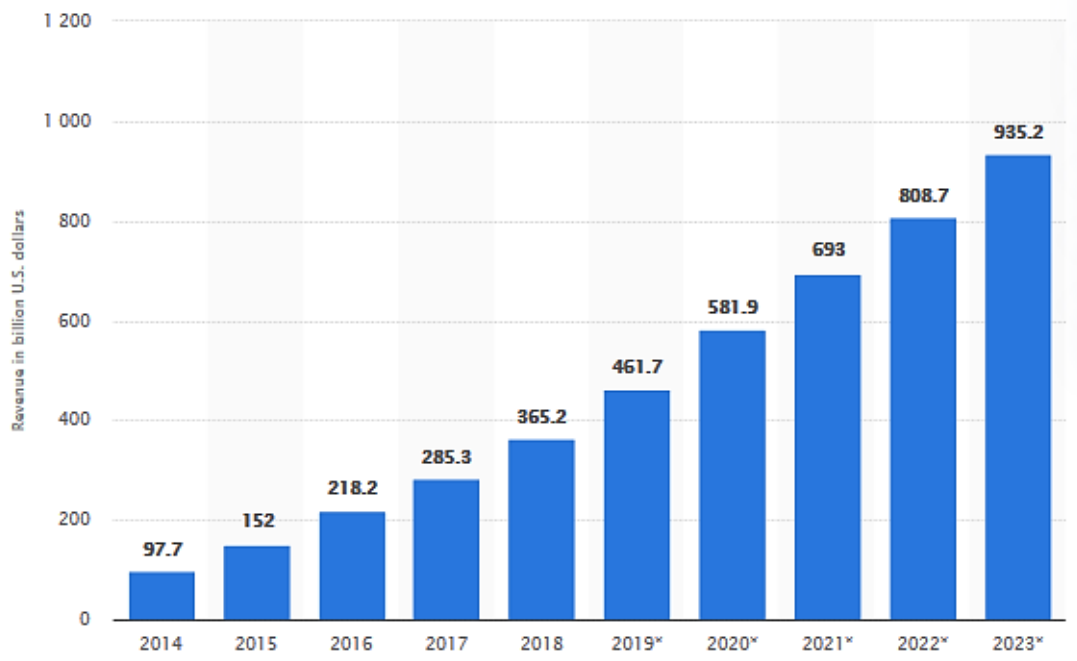

Fig. 3. Global mobile application revenue in 2014 to 2023 [10], billion dollars. 
Mobile applications in tourism are divided into three types:

1. Applications for tourists, the functionality of which includes navigation, search, booking, etc.

2. Applications for travel agencies that feature tours, promotions, and other agency features.

3. Applications for hotels, which, in turn, include hotel room reservations, as well as special guest expectations.

We will take a closer look at mobile applications for tourists.

Mobile applications in the travel area help users plan trips, book rooms, book tickets, order taxis, map routes, and much more. However, these are only the main uses of mobile travel applications, and more travel services can be provided, such as:

- $\quad$ Navigation - GPS services, route planning and maps;

- $\quad$ Social networks - updates, reviews, picture galleries, free communication, etc.;

- Mobile Marketing - contests, discounts, and notification offers;

- Safety - Medicine, emergency calls, and information on local and international health agencies;

- $\quad$ E-commerce - ticket booking, banking operations abroad, reservation, shopping.

The tourism industry uses applications to achieve greater user engagement and market penetration. Several new trends and technical factors will determine the future of the mobile tourism application.

Here are some of the innovations and trends that influence the development of mobile travel applications:

1. Real-time tracking. Real-time travel tracking applications are increasingly becoming the norm. Most private modes of transport already offer this service, as people can track the movement of their cars, buses, etc. This service only gets better as all transportation will depend on real-time tracking in the future. Public transportation agencies have begun using Internet of Things technology and GPS devices to provide real-time information about buses, trains, etc.

2. Cashless travel. Theft and cash troubles are a major security concern for tourists visiting new countries and regions for the first time. The advantage of the digital economy is that there are now several applications that allow to travel cashless and simplify all kinds of payments with one click.

3. Customized travel applications based on personal preferences. With big data and machine learning, tourism applications are evolving and getting smarter. More sophisticated travel applications will now be created for personal routes, time, budget and vehicles. Using a person's travel history, preferences, and reviews, these applications will be able to recommend and plan the best trips for the tourist.

4. Social travel planning. This joins new age technology with user recommendations. These applications help users view offers and favorites from friends and family, expert advice and consumer reviews - all of which combine to make informed decisions about their travel and tourism - including destinations, suppliers, reservations, etc. An Adweek review (a weekly U.S. publication) shows that social reinforcement is an important factor for mobile travelers, with more than 80 percent preferring recent reviews before coordinating a trip. By integrating social media and vendor reviews, travel companies can offer applications that offer sufficient social validation to potential travelers.

5. Localization. Geotargeted recommendations are very popular in many sectors, and the tourism industry is no different. Travel applications can improve the user experience by offering travelers localized offers based on their location and preferences [14].

The travel application industry has great potential for monetization and revenue generation. Today, mobile applications created for tablets and smartphones are an 
innovative means of stimulating domestic tourism and promoting investment projects. The main advantages of mobile applications: simplification of communication between the brand and the user, economic benefit and ease of use. Depending on the company's specifics and current business priorities, mobile applications can become an effective marketing tool for attracting new customers or a convenient service for working with the existing customer base.

Tourism was one of the first sectors that digitized business processes at a global scale, as a result of which online booking for flights and hotels has become a digital pioneer. As information and communication technology (ICT) has become a global phenomenon, tourism has invariably introduced new technologies and platforms.

The digital tourism sector should innovate and create new business opportunities in order to ensure the continued competitiveness, growth and sustainable development of the sector.

Digitalization is expected to continue to push the travel experience along its trajectory toward becoming smoother, more seamless and higher quality, thus contributing to the United Nations' Sustainable Development Goals (SDGs). On 25 September 2015, the United Nations General Assembly adopted the 2030 Agenda for Sustainable Development, and with it, the Sustainable Development Goals, a system of 17 goals and 169 targets through which states, civil society, and the private sector can guide and measure their contributions to sustainable development by 2030 .

The New Development Agenda is the most ambitious to date, and the 17 goals are a universal call to action to eradicate poverty, protect the planet, and ensure that all people enjoy peace and prosperity. Goals are interrelated, often the key to the success of one is solving problems that are most often related to the other.

The SDGs work in a spirit of partnership and pragmatism to make the right and appropriate choices to improve lives in a sustainable way for future generations [11].

The use of technologies, including the Internet of Things, location-based services, artificial intelligence, augmented and virtual reality, has made the tourism offer more attractive, efficient, inclusive and cost-effective, as well as socially and environmentally sustainable. It also encouraged innovation and rethinking processes to address issues such as seasonality and overcrowding, as well as developing smarter directions.

Digitalization has a positive impact on the environment and can have an even greater impact through innovation in manufacturing, intellectual assets, and efficient use of resources that contribute to a more sustainable industry.

Some of the main impacts on the sector as a whole are the development of smart travel facilitation, smart destinations and a new wave of job profiles. So let's take a closer look at each point:

- Smart travel facilitation. Similarly, the smartphone has transformed telecommunications and media, and a comprehensive smart travel model that includes smart visas, borders, security processes and infrastructure will revolutionize tourism. Through the consolidation of these tools, passengers can book their flights and check in online, get boarding passes on their smartphones, go through automatic customs gates and even confirm their boarding passes electronically on board. These measures improve both travel facilitation and safety.

- Smart destinations. "Smart destination" - a strategy with all the technology, innovation, sustainability, accessibility and inclusivity throughout the travel cycle: before, during and after the trip. "Sensible" destinations - also places of residence and tourists who take into account multilingualism, cultural characteristics and seasonality when planning tourism.

This is why smart destinations are the key to transforming the tourism sector. By continuously and accurately measuring, integrating and analyzing data for effective 
decision-making, prioritizing and anticipating problems, organizations create a seamless and engaging experience for tourists while effectively managing local resources.

Smart destinations can make tourism management more inclusive through organizations such as boards, trusts or foundations that represent all public/private stakeholders in the destination. Such destinations can help maximize access to sites, products and services, removing barriers to mobility.

Let's consider, for example, the problem of seasonality, where changes in population due to changes in tourist flows make it difficult to measure the impact of tourism. Technology-based data tools, such as remote sensors and big data management systems, can help destination managers collect and process large amounts of data to better understand the impact of seasonality on tourism and sustainability. Therefore, it can help them forecast and manage tourist flows to manage destinations more efficiently and effectively.

- Job placement. The future of travel is technology-driven, so the travel industry will require both the technical and advanced skills needed to effectively implement and manage smart initiatives. The greatest societal impact of the digital transformation in tourism may be on the sector's workforce, which directly or indirectly represents 1 in every 10 jobs in the world. As in other sectors of the economy, smart automation will change the nature of some jobs and eradicate others entirely. But growth with digital technology will also create new employment opportunities that may outpace the automation of existing roles, especially with strong growth predicted in this sector.

Startups and micro, small and medium-sized enterprises (MSMEs) - the driving forces behind technological innovation and entrepreneurship in tourism - will play an increasingly important role in developing the skills needed for the future. In this regard, the sector should give priority to strengthening start-ups and MSMEs so that they can become an integral part of the tourism value chain, as well as encourage technology- and skills-based education, training and policies that stimulate innovation and decent employment [15].

One of the major trends that travel agencies and the travel industry will have to accommodate in the future is the growing global interest in green travel. Tourism is increasingly showing a great contribution to climate change. As a result, more and more tourists have begun to realize the negative impact their travels may have on the affected regions. This has led to more and more people advocating for green travel choices. Storing information on a gadget helps to eliminate the need for paper guides, leaflets. It also makes it easier for campers, everything they need is stored right at their fingertips, and it's also eco-friendly.

One of the negative trends of digitalization is the reduction of travel agents. Due to the fact that information is becoming more accessible, the tourist is able to find and book what he needs, quite independently. Previously these tasks belonged exclusively to managers, now more and more users are acting on their own.

\section{Conclusion}

In conclusion, it should be noted that travel agency marketing methods have changed over the past few years, and many other travel agencies are using social media as a marketing tool. The most popular marketing platform in 2016 was Facebook, followed by LinkedIn and Twitter. Despite improvements in the industry, a 2017 Statista survey found that only 16 percent of respondents who would like to take spring break would "certainly" or "probably" use a travel agency to book a trip.

Travel management, like many other things, is becoming increasingly web-based. In 2016, digital travel sales in the U.S. totaled 180.6 billion dollars. According to the forecasts, that number will exceed 213 billion dollars by 2020. Such is the success of the 
online travel marketplace. The largest travel agency in the world is the online travel agency Expedia, followed by another: the Priceline group. These two online agencies were also among the preferred agencies of American travelers. A 2017 survey showed that 41 percent of travelers said they would book a trip with Expedia, and 24 percent said they would book with Priceline, ranking them first and third, respectively, in the survey [6].

The above indicates that, over time, there will be fewer travel agencies, and many people will be out of work. The available platform is the Internet, of which you need to properly create your product, marketing and customer base. However, it will not be less profitable.

\section{References}

1. The New Technology and Travel Revolution. WAM Global Growth Agents. https://www.wearemarketing.com.

2. T. I. Alyunova, I. P. Nikolayeva, O. A. Petrov, L. V. Semenova, S. V. Kiselev, G. F. Yusupova, A. N. Mayorova, N. M. Korsunova, Journal of Sustainable Development, 8(6), 90 (2015)

3. Lisa Gevelber, Oliver Heckmann Travel trends: 4 mobile moments changing the consumer journey. Think with Google (2015) https://www.thinkwithgoogle.com.

4. Augmented reality. Design Dossier Marketing Company. http://3dday.ru.

5. Internet of Things. IT-Enterprise. https://www.it.ua.

6. How the Internet of Things (IoT) can Benefit the Travel Industry. Knowledge Platform for the Hospitality \& Travel Industry. https://www.revfine.com.

7. Artificial Intelligence.What is Artificial Intelligence? How Does AI Work? Technology of Built (2019) https://builtin.com.

8. AI in IT. How Artificial Intelligence will Transform the IT industry. Softengi - a Digital Transformation Company. https://softengi.com.

9. What is Big Data: most important things about big data were collected // Rusbase, an independent technology and business publication. https://rb.ru.

10. Worldwide mobile app revenues in 2014 to 2023. Statista. https://www.statista.com.

11. UNWTO World Tourism Barometer. World Tourism Organization, Madrid (2020)

12. Direct and total contribution of travel and tourism to GDP from 2006 to 2019. Statista. https://www.statista.com.

13. Number of mobile phone users worldwide from 2015 to 2020. Statista. https://www.statista.com.

14. Tourism Mobile App Development. Rishabh Software. https://www.rishabhsoft.com.

15. Digital Transformation. World Tourism Organization. https://www.unwto.org. 